\title{
Percepción social sobre la inseguridad ciudadana en Huancayo
}

\author{
Social perception about citizen insecurity in Huancayo
}

\author{
Marisol Condori A.!'y Gustavo A. Reyna A." \\ (1) Facultad de Sociología, Universidad Nacional del Centro del Perú \\ Email: betreyna23@hotmail.com
}

\section{Resumen}

El objetivo del estudio fue describir la percepción sobre la inseguridad ciudadana en el distrito de Huancayo. Métodos: Investigación de tipo básica, nivel descriptivo, diseño no experimental transversal descriptivo simple. Resultados: Los hallazgos demuestran que el $56.4 \%$ de ciudadanos percibe a la inseguridad como muy grave; el $93.7 \%$ percibe que vivir en Huancayo es inseguro; el $54.6 \%$ considera a la delincuencia como principal problema en el distrito de Huancayo; el 81.8\% de víctimas de la delincuencia no denunciaron el robo, el $51.6 \%$ no denuncia porque considera que no pasa nada y no le hacen caso; las medidas que toman los ciudadanos frente a la inseguridad son: cambiar o colocar cerraduras y/o candados, instalar alarmas y/o videocámaras de seguridad, colocar rejas en las viviendas, realizar acciones conjuntas con los vecinos, colocar cercos de seguridad, alambre de púa o murallas, contratar vigilancia privada en las calles y comprar un perro guardián.

Palabras Claves: seguridad e inseguridad ciudadana, percepción, victimización, estrategias de seguridad

\begin{abstract}
Objective: Describe the perception of citizen insecurity in the district of Huancayo. Methods: Basic type research, descriptive level, simple descriptive transversal non-experimental design. Results: The findings show that $56.4 \%$ of citizens perceive insecurity as very serious; $93.7 \%$ perceive that living in Huancayo is insecure; $54.6 \%$ consider crime as the main problem in the district of Huancayo; $81.8 \%$ of crime victims did not report the theft, $51.6 \%$ did not report it because they believe that nothing happens and they ignore it; the measures taken by citizens in the face of insecurity are: changing or placing locks and / or locks, installing security alarms and / or video cameras, placing grilles in houses, carrying out joint actions with neighbors, placing security fences, wire Barbed wire or walls, hire private surveillance in the streets and buy a watchdog.
\end{abstract}

Keywords: security and citizen insecurity, perception, victimization. Security strategies 


\section{Introducción}

En el Perú, al igual que en muchos otros países de América Latina, la problemática social de la inseguridad ciudadana es creciente, ya que implica no solo el incremento de la delincuencia, sino otros factores que comprenden riesgo y peligro para la población. La inseguridad ciudadana es una amenaza permanente en la mayoría de las ciudades grandes y ciudades intermedias del país. Según la última encuesta de Proética (I) la delincuencia, la corrupción y el consumo de drogas son los problemas que más preocupan a la opinión pública. Dentro de estos tres problemas la delincuencia figura como el primer y principal problema que afecta a la sociedad peruana. Esto se debe a que los hechos delincuenciales en todas sus modalidades se han incrementado significativamente en todo las grandes ciudades del país, aspecto que se ve reflejado también en el incremento, en los últimos diez años de los índices de percepción social del fenómeno de la delincuencia, en el 2008, el 41\% de la población encuestada consideraba que este hecho era una amenaza para la seguridad ciudadana, en el 2015 el $62 \%$ el opinaba que la delincuencia se había incrementado y era el principal problema a resolver por el Estado. De igual manera, en la encuesta nacional realizada por el Instituto de Opinión Publica de la PUCP, en el mes de marzo del 2016, el 80\% de la población considera que el primer problema más álgido el país es la delincuencia e inseguridad ciudadana (2).

La investigación se realizó con el objetivo de describir la percepción sobre la inseguridad ciudadana en el distrito de Huancayo. Para lo cual se recurrió a un cuestionario aplicado a 383 ciudadanos, quienes nos brindaron información valiosa. La misma que fue comparada con Lagos y Dammer (3) en su estudio "La Seguridad Ciudadana. El problema principal de América Latina. 2012 "; Perucamaras (4) "Percepción de inseguridad alcanza el 91.5\% en la Macro Región Sur; Quinteros (5) "Delitos del espacio público y el problema de la "cifra negra": una aproximación a la no-denuncia en Chile" y; Zechmeister (6) "La cultura política de la democracia en las Américas, 2014: Gobernabilidad democrática a través de 10 años el Barómetro de las Américas" Con la presente investigación se pretende contribuir al avance de conocimientos sobre la problemática de la inseguridad ciudadana y de esta manera sumar al avance de las ciencias sociales.

\section{Materiales y métodos}

La investigación es de tipo básica, ya que busca ampliar conocimientos sobre la percepción que tienen los ciudadanos respecto a la inseguridad del distrito de Huancayo; el enfoque metodológico es cuantitativo, ya que se aplicó cuestionarios a los ciudadanos para obtener información sobre el tema en cuestión; el nivel es descriptivo, con un diseño no experimental transversal descriptivo simple; la muestra corresponde a 383 ciudadanos del distrito de Huancayo, entre varones y damas, a quienes se les aplicó un cuestionario.

\section{Resultados}

La situación en la que vivimos los pobladores del distrito de Huancayo y del Perú, es preocupante, ya que la inseguridad ciudadana que padecen pone en riesgo su integridad y sus vidas.

Tabla I. Percepción sobre la situación de la inseguridad ciudadana a nivel nacional $(n=383)$

\begin{tabular}{|l|c|c|}
\hline \multicolumn{1}{|c|}{ Calificación } & Ciudadanos & $\%$ \\
\hline Muy grave & 216 & 56,4 \\
\hline Grave & 142 & 37,1 \\
\hline Poco grave & 20 & 5,2 \\
\hline Nada grave & 5 & 1,3 \\
\hline
\end{tabular}

Los resultados muestran que el $56.4 \%$ de encuestados califican a la inseguridad ciudadana en el país como un tema muy grave, el 37.1\% como grave; el 5.2\% como poco grave; y sólo el 1.3\% como una situación nada grave. Por lo tanto, un significativo porcentaje 93.7\% considera el tema de la inseguridad ciudadana como "GRAVE", evidenciando el alto nivel de inseguridad que existe en el distrito de Huancayo y a nivel nacional.

Por otro lado, a la pregunta si se siente seguro(a) o inseguro(a) viviendo en Huancayo, la gran mayoría de ciudadanos(as) muestra un sentimiento de inseguridad, tal como se visualiza en la figura I.

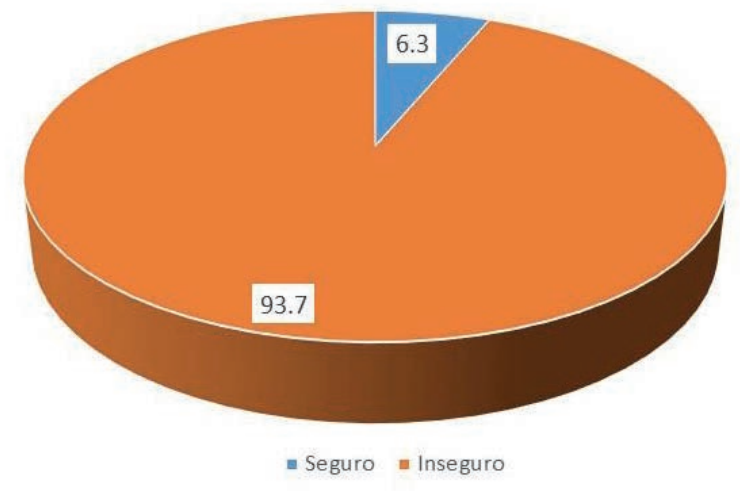

Figura I. Percepción sobre la inseguridad de vivir en el distrito de Huancayo

Los resultados dan a conocer cómo los ciudadanos de este distrito perciben el ámbito donde transcurre su existencia en un contexto de falta de seguridad, que convierte a una sociedad en un espacio vulnerable 
pues se combina con la sensación de impotencia para hacerle frente y sancionarla lo que implica un crecimiento desordenado donde no existen las más elementales normas de convivencia, además vemos que un significativo porcentaje (93.7\%) de encuestados se siente inseguro de vivir en el distrito de Huancayo, y solo el 6.3\% restante de ciudadanos se sienten seguros.

Los datos antes mostrados, nos conllevan a preguntarnos sobre el principal problema que afecta a los ciudadanos en el distrito de Huancayo, y los resultados muestran a la delincuencia como una situación preocupante.

Tabla 2. Principal problema que afecta a los ciudadanos

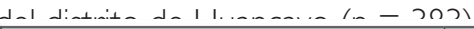

\begin{tabular}{|l|c|c|}
\hline Problema & Ciudadanos & $\%$ \\
\hline Delincuencia & 209 & 54,6 \\
\hline Pandillaje & 43 & 11,2 \\
\hline Pobreza & 33 & 8,6 \\
\hline Limpieza/basura & 13 & 3,4 \\
\hline Desempleo & 21 & 5,5 \\
\hline Drogadicción & 15 & 3,9 \\
\hline Prostitución & 18 & 4,7 \\
\hline Alumbrado público & 1 & 0,3 \\
\hline Alcoholismo/cantinas/bares & 28 & 7,3 \\
\hline Transporte/tráfico & 2 & 0,5 \\
\hline
\end{tabular}

Todas las ciudades entre ellas sus distritos ostentan una serie de problemas y necesidades insatisfechas. El distrito de Huancayo, no es la excepción, en la tabla 2 apreciamos que se percibe a la delincuencia común como problema principal (54.6\%) y se constata la existencia de problemas colaterales como el pandillaje ( I 1.6\%), drogadicción (3.9\%) y alcoholismo (7.3\%), como insumos del mismo. Juntos totalizan el $77.4 \%$. Los problemas de pobreza (8.6\%) y desempleo (5.5\%) pueden contribuir a que el problema de la delincuencia se incremente.

La delincuencia que se vive en el distrito de Huancayo, genera consecuencias perjudiciales a la ciudadanía, atentando contra su salud, física y psicológica, tal es así que los ciudadanos víctimas de actos delictivos, perciben haber sido dañados, así lo muestra la siguiente tabla.
Tabla 3. Principal daño que sufrió el ciudadano víctima de un acto delictivo $(n=154)$

\begin{tabular}{|l|c|c|}
\hline Daño & Ciudadanos & $\%$ \\
\hline Físico & 26 & 16.9 \\
\hline Psicológico & 90 & 58.4 \\
\hline Ambos & 38 & 24.7 \\
\hline
\end{tabular}

Como señaláramos antes, en la victimización primaria luego del ataque sufrido lo más dañino (aparte de la posible pérdida material, que ya es grave) son las secuelas que deja la agresión y estos pueden ser daño físico, psicológico o ambos. Es importante detenerse en lo psicológico puesto que este es el campo de las percepciones, es el espacio subjetivo donde se generan los miedos, en nuestro caso, el miedo a la calle, que al convertirse en una endemia social generan las representaciones sociales sobre lo peligroso que es desplazarse por el distrito en general o por alguna(s) calle(s) del mismo. Los resultados mostrados en la tabla anterior confirman lo señalado, de las personas que han sufrido victimización por un acto delictivo; el 58,4\% ha sufrido daño psicológico, de estos el 24,7\% presenta doble secuela, ya que presenta daño físico y psicológico simultáneamente; el 16,4\% de ciudadanos señala haber sufrido solo daño físico.

Frente a la situación de inseguridad en la cual los ciudadanos del distrito de Huancayo fueron víctimas, no todos presentan la denuncia respectiva, así lo muestra la siguiente tabla.

Tabla 4. Ciudadanos que presentaron la denuncia tras ser víctimas de robo $(n=154)$

\begin{tabular}{|l|c|c|}
\hline Denuncio & Ciudadanos & $\%$ \\
\hline Si & 28 & 18,2 \\
\hline No & 126 & 81,8 \\
\hline
\end{tabular}

Cuando se es víctima de una agresión delictiva, la reacción lógica es buscar alguna protección y lo primero que piensa es en acudir a la policía a denunciar el hecho con la probabilidad de recuperar lo hurtado y la captura del delincuente a quien le debería caer el peso de la ley. Se espera de la policía, como de toda autoridad, medidas racionales que garanticen la seguridad de las personas, receptividad, asesoría y orientación cuando se es víctima de una agresión, pero sucede que esos servicios son deficientes y esa es la percepción que se tiene de la policía y las instituciones jurídico penales. Instituciones deficientes, donde se corre el riesgo de tener una experiencia negativa. Además, la victima recurre ante las autoridades judiciales, ente superior donde debe castigarse al delincuente y resarcir a la víctima, pero estas expectativas se ven defraudadas. Se produce un choque entre las expectativas del victimado y la realidad 
institucional. Estos son los ámbitos de la victimización secundaria, donde se experimenta una fuerte sensación de que nuestros derechos están siendo violados, hechos que incrementan los daños psicológicos y a veces patrimoniales de la víctima, se enfrenta a una sensación de pérdida de tiempo y malgasto del dinero, además de la frustración y el ninguneo producto del actuar de los burócratas.

En algunos casos la víctima es tratada como culpable y se pone en duda sus testimonios. Esta es otra de las representaciones sociales, policías y autoridades deficientes e ineficaces, consideración por la cual el mayor porcentaje de víctimas optan por no efectuar la denuncia.

El resultado anterior conlleva a conocer las razones por las cuales los ciudadanos no presentan denuncias después de haber sido víctimas de delincuentes.

Tabla 5. Razones por las que el ciudadano no presento la denuncia $(n=126)$

\begin{tabular}{|l|c|c|}
\hline Razones & Ciudadanos & $\%$ \\
\hline $\begin{array}{l}\text { No pasa nada, si lo denuncio no } \\
\text { me hacen caso }\end{array}$ & 65 & 51.6 \\
\hline $\begin{array}{l}\text { Falta de tiempo/Trabajo por eso } \\
\text { no puedo }\end{array}$ & 19 & 15.1 \\
\hline No sabía quién me robo & 14 & 11.1 \\
\hline $\begin{array}{l}\text { Porque solo fue un intento de } \\
\text { robo }\end{array}$ & 4 & 3.2 \\
\hline $\begin{array}{l}\text { Me asusté/Tuve miedo/Temor a } \\
\text { represalias }\end{array}$ & 8 & 6.3 \\
\hline Se dieron a la fuga & 11 & 8.7 \\
\hline No sabe/ no quiso/No le creerían & 1 & 0.8 \\
\hline Para evitarse problemas & 3 & 0.8 \\
\hline Otros & & 2.4 \\
\hline
\end{tabular}

Los resultados demuestran una representación social de desconfianza hacia las autoridades, ya que la mayoría de encuestados 51,6\% no cree en la eficacia de la policía, ya que "no pasa nada/si lo denuncia no le hacen caso", el I5,I\% no lo hizo por falta de tiempo/ trabajo por eso no puedo.

Frente a la situación de inseguridad e ineficacia de las autoridades, los ciudadanos se ven en la necesidad de tomar sus propias medidas de seguridad, tal como se visualiza en la siguiente tabla.
Tabla 6 Principales medidas de seguridad que utilizan en su hogar los ciudadanos $(n=383)$

\begin{tabular}{|c|c|c|c|c|c|c|}
\hline \multirow{3}{*}{ Medidas de seguridad } & \multicolumn{6}{|c|}{$\begin{array}{c}\text { Tres primeras medidas de } \\
\text { seguridad }\end{array}$} \\
\hline & \multicolumn{2}{|c|}{ Primera } & \multicolumn{2}{|c|}{ Segunda } & \multicolumn{2}{|c|}{ Tercera } \\
\hline & $f$ & $\%$ & & $\%$ & f & $\%$ \\
\hline $\begin{array}{l}\text { Cambiar } 0 \text { colocar } \\
\text { cerraduras y/o candados }\end{array}$ & 243 & $\begin{array}{c}63 \\
4\end{array}$ & & & 6 & 1,6 \\
\hline $\begin{array}{ll}\text { Colocar cercos } & \text { de } \\
\text { seguridad, alambre } & \text { de } \\
\text { púa o murallas } & \end{array}$ & 58 & $\begin{array}{c}15 \\
1\end{array}$ & 60 & $\begin{array}{c}15 \\
7\end{array}$ & 5 & 1,3 \\
\hline Colocar rejas & 36 & 9,4 & 88 & $\begin{array}{c}23 \\
0\end{array}$ & $\begin{array}{l}3 \\
1\end{array}$ & 8,1 \\
\hline $\begin{array}{lr}\text { Instalar alarmas } & \text { y/o } \\
\text { videocámaras } & \text { de } \\
\text { vigilancia } & \\
\end{array}$ & 38 & 9,9 & $\begin{array}{c}11 \\
5\end{array}$ & $\begin{array}{c}30 \\
0\end{array}$ & $\begin{array}{l}4 \\
0\end{array}$ & 10,4 \\
\hline $\begin{array}{l}\text { Contratar vigilancia } \\
\text { privada en la calle. }\end{array}$ & 5 & 1,3 & 43 & $\begin{array}{c}11 \\
2\end{array}$ & $\begin{array}{l}4 \\
0\end{array}$ & 10,4 \\
\hline $\begin{array}{l}\text { Realizar } \quad \text { acciones } \\
\text { conjuntas con sus } \\
\text { vecinos }\end{array}$ & 3 & 0,8 & 57 & $\begin{array}{c}14 \\
9\end{array}$ & $\begin{array}{l}9 \\
0\end{array}$ & 23,5 \\
\hline Contratar seguros & & & 9 & 2,3 & $\begin{array}{l}6 \\
0\end{array}$ & 15,7 \\
\hline $\begin{array}{l}\text { Comprar un perro } \\
\text { guardián }\end{array}$ & & & 8 & 2,1 & $\begin{array}{l}6 \\
9\end{array}$ & 18,0 \\
\hline Adquirir armas de fuego & & & 3 & 0,8 & $\begin{array}{l}2 \\
4\end{array}$ & 6,3 \\
\hline $\begin{array}{l}\text { Cambiarse de vivienda o } \\
\text { lugar de residencia }\end{array}$ & & & & & $\begin{array}{l}1 \\
1\end{array}$ & 2,9 \\
\hline Otra & & & & & 7 & 1,8 \\
\hline
\end{tabular}

En la Tabla anterior se observa que la mayoría de los encuestados $(65,0 \%)$ tienen como prioridad cambiar o colocar cerraduras y/o candados, instalar alarmas y/o videocámaras de seguridad (50,3\%), colocar rejas en las viviendas (40,5\%), realizar acciones conjuntas con los vecinos (39,2\%). colocar cercos de seguridad, alambre de púa o murallas (32,1\%), contratar vigilancia privada en las calles $(22,9 \%$ ) y comprar un perro guardián $(20,1 \%)$, siendo estas las principales medidas que consideran los entrevistados.

\section{Discusión}

La prevalencia de la delincuencia en el distrito de Huancayo, ha generado que el $93.7 \%$ de la población tenga una percepción negativa respecto a la seguridad ciudadana. La mayoría de la población tiene la sensación de que viven en espacios públicos y privados inseguros, por lo que se sienten amenazados y con riegos e ser víctimas de un delito. Este porcentaje es significativamente alto, así lo señala el estudio realizado por Lagos y Dammert (3) quienes muestran que en Junín la delincuencia representa un $81,2 \%$ y a nivel Nacional $89,1 \%$, siendo incluso internacionalmente más alto que la ciudad de México (7I\%), Venezuela (61. \%); El Salvador y Guatemala con el $51 \%$ respectivamente. Por otro lado a través de los datos mostrados por Perú Cámaras (4) la delincuencia en Huancayo es similar a otras regiones y ciudades como: Puno (92.8\%), Tacna, (93.5\%), Arequipa (92.3\%), Cuzco (90.1\%), Lima (90\%) donde los niveles percepción de la inseguridad ciudadana son 
superiores al 90\%. En otras regiones y ciudades del país la percepción de inseguridad también son significativamente altas, como Madre de Dios 89\%, Trujillo $82 \%$ y Moquegua $84.5 \%$

Los resultados también muestran a la delincuencia como el principal problema que afecta a los ciudadanos en el distrito de Huancayo, quienes se ven afectados física y psicológicamente, y en su mayor porcentaje (81.8\%) no denuncian el robo, porque perciben que si denuncian, las autoridades no les hacen caso o simplemente no pasa nada (5 I.6). Similar situación halló Quinteros ${ }^{(5)}$ dando a conocer que, quienes no tienen ninguna confianza en las policías, son quienes, en mayor proporción, no denuncian.

Frente a la delincuencia como principal problema y a la percepción negativa que tienen los ciudadanos hacia la Policía y otras autoridades, se ven obligados a tomar medidas de seguridad en sus hogares, tales como cambiar o colocar cerraduras y/o candados, instalar alarmas y/o videocámaras de seguridad, colocar rejas en las viviendas, realizar acciones conjuntas con los vecinos, colocar cercos de seguridad, alambre de púa o murallas, contratar vigilancia privada en las calles y como ultima estrategia comprar un perro guardián. Acuden a estas estrategias por miedos, temores de ser víctimas de la inseguridad y frente a la inoperancia de la policía $\mathrm{Na}$ cional y el Serenazgo. Estas estrategias se han Hecho cotidianas en casi todas las grandes ciudades, es así que en la ciudad de México el 65.5\% de las viviendas usan mecanismos de protección en las viviendas de la ciudad (barda alta, ventanas con barrotes, cerraduras especiales, etc.) ${ }^{(5)}$

\section{Conclusiones}

Huancayo es un distrito con un significativo nivel de inseguridad ciudadana, ya que presenta como principal problema la delincuencia.

La presencia de la delincuencia común en el distrito de Huancayo ha dado lugar a que la población tenga una percepción negativa hacia la inseguridad ciudadana.

El mayor porcentaje de víctimas de la delincuencia en el distrito de Huancayo no denuncia debido a una percepción negativa e ineficiente hacia la Policía.

La percepción de la existencia de problemas de inseguridad ciudadana y los altos índice de victimización ha generado que muchas personas y familias del distrito de Huancayo implementen estrategias de protección. Acuden a estas estrategias por miedos, temores de ser víctimas de la inseguridad y frente a la inoperancia de la policía Nacional y el Serenazgo.

\section{Referencias}

I. Proética. Novena encuesta Nacional sobre corrupción. (20।5). Lima, Proética. .

2. López, N. La inseguridad ciudadana, el principal problema del país. PUCP, Lima. (20I6). En: iop.pucp. edu.pe/columna-opinon/la-inseguridad-ciudadana-principal-problema-del-pais.

3. Lagos, M. y Dammer, L. La Seguridad Ciudadana. El problema principal de América Latina. (20I2). En: http:://www.latinobarometro.org/documentos/LATBD_ La_seguridad_ciudadana.pdf

4. Perucamaras. Percepción de inseguridad alcanza el $91.5 \%$ en la Macro Región Sur. En Diario Gestión, 23 de septiembre del (20/5). En: Gestion. pe/economia/percepcion-inseguridad-alcanza-9 I 5-macro-region-sur-senala-perucamaras-21435।6

5. Quinteros, D. Delitos del espacio público y el problema de la "cifra negra": una aproximación a la no-denuncia en Chile". Polít. crim. Vol. 9, № 18 (Diciembre (2014) En: http://www.scielo.cl/pdf/politcrim/v9n I8/ art I2.pdf

6. Zechmeister, E. La cultura política de la democracia en las Américas, 2014: Gobernabilidad democrática a través de 10 años el Barómetro de las Américas, (20|4). 